Session 2793

\title{
The CURIE River Basin: Introduction to Engineering in a Social Context
}

\author{
K-Y. Daisy Fan, Krishna S. Athreya, Robin J. Burt \\ School of Civil \& Environmental Engineering/ Women's Programs in Engineering, \\ Cornell University, Ithaca, New York
}

\begin{abstract}
The Elements: 40 academically gifted high school girls; a nationally recognized engineering college, seven days.

The Task: Create a sense of excitement about and an awareness of the limitless possibilities in engineering.

Cornell's Strategy: The CURIE Academy, a week-long, residential summer engineering experience comprising field-specific information sessions, panel discussions, team and leadership building, hands-on activities, all focusing on a complex, multi-disciplinary project. The CURIE 2000 project was a water quality management problem that highlighted technical, social, political, and economic aspects of "real life" engineering. The project was created and delivered by a graduate student in Civil and Environmental Engineering, with support from five undergraduate Program Assistants who facilitated the group interactions and provided social mentoring for the girls. The challenges and rewards of such an ambitious project were plentiful. The CURIE experience not only increased the girls' awareness of the opportunities and technical challenges in engineering, but also allowed them to experience the complex interaction among our society, technology, and environment - an issue not often addressed in the early stages of engineering education.

Introduction

Engineering continues to be a field where women and people of color are highly underrepresented, with women making up barely $20 \%$ of the undergraduate population in engineering in the United States and minorities making up less than 10\%. The recent report of the Commission on the Advancement of Women and Minorities in Science, Engineering and Technology (CAWMSET) reiterates the national need for broadening the accessibility to quality SET pre-college education, particularly for underrepresented minorities. ${ }^{2}$ Institutions and colleges of engineering are recognizing this need; a variety of programs currently exist to enhance the pre-college pipeline to engineering by providing early education opportunities on university campuses.
\end{abstract}


The CURIE Academy at Cornell University is a pre-college program designed to provide a broad engineering experience to 40 high school girls — students who excel in math and science, have broad interests, and show promise as team builders and/or leaders-during one week in the summer. The program has been in existence since 1996 and gives special attention to the recruitment of underrepresented minority girls. The students, who are at the end of their sophomore or junior year in high school, live in Cornell University dormitories and experience as much engineering as can be coherently built into the seven-day timeframe. They work in teams on a core project, participate in seminars and workshops, and are exposed to a variety of engineering fields through hands-on sessions. Five Cornell engineering students serve as Program Assistants (PAs) and peer mentors during the week.

The goal of the core project was to provide the students with a broad and challenging engineering experience, one that would allow them to understand engineering as "design under constraint," where nature is only one of the operating constraints, not necessarily the most limiting or most difficult one. ${ }^{3}$ We also wished to provide a student-centered learning environment by presenting an open-ended situation that would call upon their critical thinking and creative faculties. Following the suggestions of Felder and Brent ${ }^{4}$ for student centered learning, we designed a project where the participants had to identify the problem constraints through role-playing exercises, work in teams, and finally present and justify their findings and recommendations in a public setting. While our participant population was high school juniors, their academic profiles indicated a higher level of performance and we felt they would benefit from an early exposure to a sophisticated, integrative process. In this approach, we were in line with Bordogna' $\mathrm{s}^{5}$ call for restructuring engineering education in the $21^{\text {st }}$ century, using NSF's guidelines for “.... recognition of engineering as an integrative process in which analysis and synthesis are supported with sensitivity to societal need and environmental fragility.",

\section{Program Structure}

The CURIE Academy is a week-long, summer residential program designed to serve 40 high school girls each year. It is jointly administered by the office of Women's Programs in Engineering and the Engineering Minority Programs Office (EMPO). The goals are as follows:

- Engage the students' imaginations about the possibilities available to them through the study of engineering and technical fields.

- Give them a working understanding of the different engineering specializations.

- Impress upon them the vitality that results when people of differing backgrounds, academic specializations, and experience come together in teams to solve complex problems.

\section{Recruitment and Selection}

The students are recruited from schools around the country targeted by the College of Engineering's admissions office. Students must have a minimum GPA of 3.5 (or equivalent), top grades in math and science, and a letter of endorsement from a math or science teacher or a school counselor. Writing abilities are weighed heavily, judged from the essay each student submits. In addition students are sought who demonstrate leadership and the ability to work cooperatively with others, community involvement and/or service, and breadth of extracurricular interests. 


\section{Program Content}

The program begins with dinner on a Sunday night in mid-July, followed that same evening by introductions, orientation, and team building activities. The 40 students are divided into groups of eight, each assigned to one of the five PAs. The PAs are engineering undergraduates hired months ahead of time to help design ice-breakers and team building activities, to support the core project, and to attend the students around the clock during the week of the program.

The academic center of the week is the Engineering Project, a multi-day experience designed around problems that engineers routinely face. The project generally is centered in one of the engineering disciplines, however emphasis is placed on the fact that engineers rarely, if ever, work alone, and projects rarely, if ever, stay neatly within the bounds of one engineering discipline. Student teams explore aspects of the project through lecture (as little as possible), labs, computer simulation and optimization, and trial and error. Eventually, they create project presentations that are given to an audience of their fellow students, parents, engineering faculty and staff on the final Saturday of the program.

Surrounding this central experience are field sessions in which engineering faculty members present their departmental disciplines and their work in creative, interactive ways. Increasingly, faculty members represent themselves as members of teams working across disciplines to solve problems of social relevance. In addition to these academic experiences, students engage in activities that seek to increase their awareness of the realities of post-secondary education. Undergraduate panels address questions about college selection, classes and course load, faculty relations, and social issues. The College Admissions office gives a talk on how to prepare for college and an "insider's look" at the admissions process in general (not specific to Cornell). There are social activities, athletic opportunities, tours, and evenings in the dorms with the PAs facilitating fun and interaction. It is a dizzying schedule, sometimes an exhausting one (Figure 1). Students can be heard complaining about the whirlwind pace, but when the post-program surveys are turned in, the CURIE experience is applauded year after year.

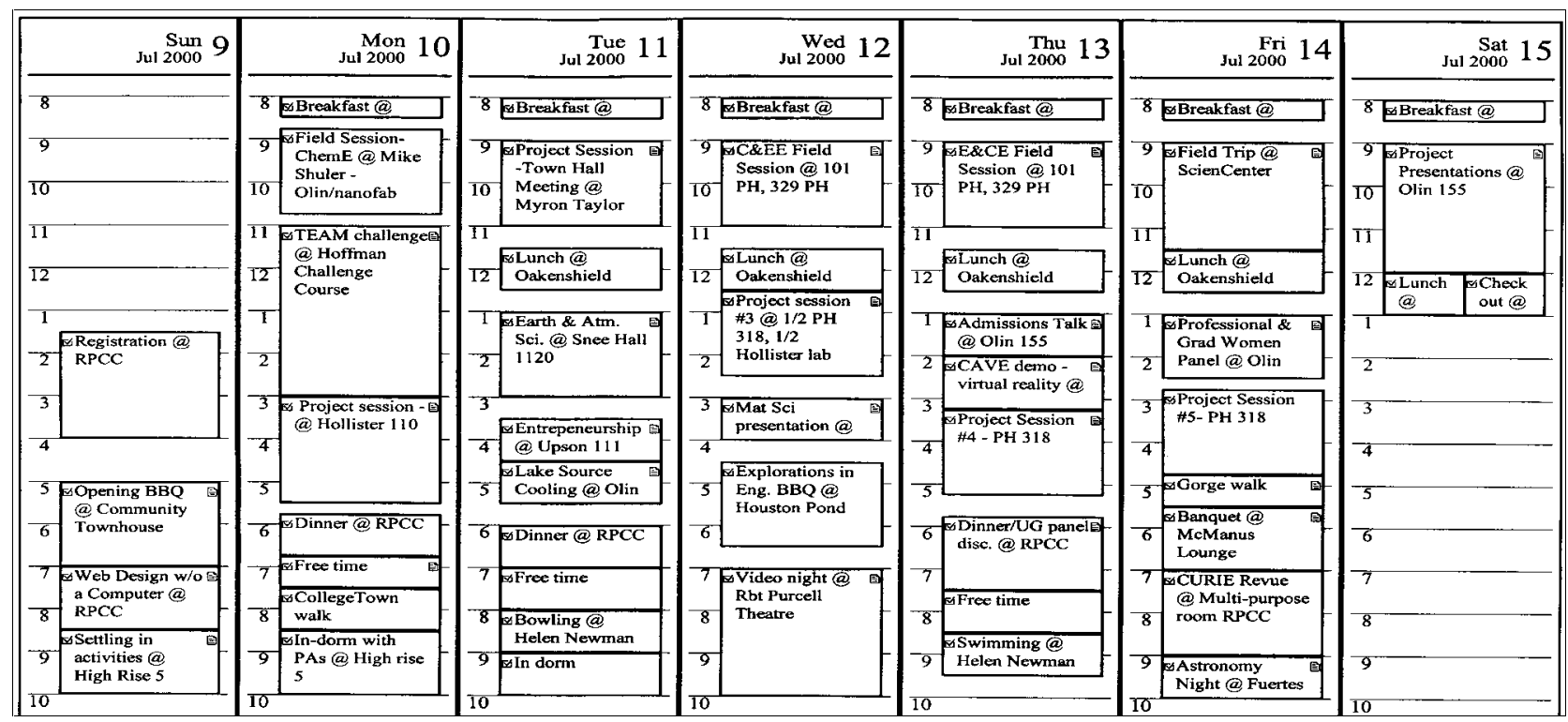

Figure 1. Schedule of 2000 CURIE 
Core Project: Water Quality Modeling and Management

The central group project for CURIE Academy 2000 encompassed the engineering fields of environmental systems, operations research, and environmental engineering. The participants were asked to identify the water quality problems in the fictitious Curie River Basin and design water quality management strategies that would maintain water quality but not stifle the regional economy. The project could be described best by the "job ad" given to the participants, shown in Figure 2.

\section{Curie River Water Quality Management Study}

Curie River Authority is in the process of formulating a comprehensive water quality management program and requires a preliminary study that will identify main water quality problems and effective regulatory strategies in the Curie River Basin. The preliminary study will include the development of a simulation model of the river basin, an optimization model that can identify economical water quality management strategies, and recommendations to Curie River Authority on effective regulatory strategies for the river basin.

The preliminary water quality management study must include the following:

- Identification of the major water quality problems in the Curie River Basin

- Extension of the water quality simulation model used by Curie River Authority to predict future water quality trends

- Evaluation of the potential water quality impact of the proposed Marie Products Inc. expansion on Curie River

- Recommendations on potential water quality policies for the Curie River Basin.

A public meeting on the state of water quality in the Curie River Basin will be held at 10:00 am on July 11, 2000, in room 390, Myron Taylor Hall. The panel will include representatives from industries and municipalities, Friends of Curie River, and other interested parties. For more information, contact Daisy Fan at Curie River Authority.

Figure 2. Project statement given as an advertisement

The main objective of the group project was to have the participants take part in solving an engineering problem in teams. This project had both technical and social constraints - a realistic engineering problem that highlighted the human face of engineering. The specific learning objectives included the following:

Recognize that

- Defining the problem is the first step of engineering problem solving

- Engineering is more than technical problem solving-environmental, social, and economic considerations are often involved

- Simulation and optimization as well as physical experimentation are useful tools in

Be able to engineering

- Identify key problems and define objectives of a solution

- Design simple water quality management policies

- Evaluate policies using water quality simulation and optimization models (software DESERT $^{7}$ )

- Present policy recommendations 
This water management project was designed to emphasize the process of engineering rather than a product from engineering. In particular, the students needed to define the problem and set the objective of the solution themselves during the first two project sessions. The girls then designed their solutions (water quality management policies) and used simulation and optimization to evaluate these solutions. Finally, they prepared and gave professional presentations on their policy recommendations. The planning and delivery of this complex project involving social and economic issues related to engineering in six two-hour sessions was a significant challenge. Table 1 shows the ambitious project schedule.

Table 1. Project schedule

\begin{tabular}{|c|l|}
\hline Day & Activity or Task \\
\hline 1 & $\begin{array}{l}\text { Introduction to water quality management } \\
\text { Walk along Cascadilla Creek-how to model a real waterway in one dimension }\end{array}$ \\
\hline 2 & Mock town hall meeting_-gather information on river system \\
\hline 3 & $\begin{array}{l}\text { Water quality analysis in the environmental engineering laboratory } \\
\text { Water quality modeling_introduction to software DESERT }\end{array}$ \\
\hline 4 & Water quality modeling_design and evaluate policies \\
\hline 5 & $\begin{array}{l}\text { Water quality modeling_design and evaluate policies } \\
\text { Formulate and prepare policy recommendation }\end{array}$ \\
\hline 6 & Presentation \\
\hline
\end{tabular}

Like most realistic engineering problems, there was not a unique best solution. The students were encouraged to consider the socio-economic issues as they evaluated alternative solutions to the technical problem. The mock town hall meeting $\left(2^{\text {nd }}\right.$ project session) highlighted the socioeconomic issues and the importance of public participation in environmental analyses. The other project sessions focused on technical analyses. The students brought together all these different components in their final presentations and responded to questions from their colleagues, staff members, and the "public."

\section{Program Feedback}

The participants in the CURIE 2000 experience responded to the core project in the classic manner of students in problem-based learning situations. ${ }^{8}$ The initial reaction was a high level of frustration and anxiety at being in a vaguely defined situation and facing an outcome that did not have a unique solution. However, even before they resolved these emotional reactions, the participants began grappling with the task within their assigned teams. As evidenced by the quality of their final presentations, these students successfully sorted through a maze of complex issues and parameters and were able to clearly articulate recommendations based on their technical study combined with socio-political-economic-equity issues. What emerged from their feedback was that this experience challenged their existing ideas about engineering, stretched their creativity, and took them out of their comfort zone. All of the students, however, acknowledged the program was a valuable learning experience, one that they would participate in all over again and recommend to others. ${ }^{9}$ 
Twenty of the thirty-six respondents felt academically challenged by the program, five felt somewhat challenged. Of the even 11 who said they were not challenged, comments were made about the project being the significant learning piece, even when they did not always enjoy it. All 36 respondents agreed the program gave them a broader understanding of the variety of engineering fields and an appreciation of the value of teamwork. Thirty-two participants felt the program gave them a deeper understanding of engineering as a field of study and as a career.

\section{Participant Quotes:}

Wouldn't trade this experience for the world

Excellent in showing what engineering is all about

Enjoyed the entire program. Very challenging

Would definitely do it again

Project was kind of tough

The project was really confusing

Challenged me and caused me to be more creative

Felt challenged with some computer activities, but in a good way

Project was difficult and confusing, but worthwhile in the end

From the perspective of the program administrators and the faculty advisory committee, the participants in CURIE 2000 experienced engineering education at a level of sophistication rarely available in the early stages. They engaged fully in the process, right up to the project presentations when they were asked probing questions by their peers-questions requiring them to justify their approaches and solutions. In the future, we feel that it may be worthwhile to acknowledge to the participants at the beginning of the program that a certain level of discomfort and frustration may be part of the process and does not impede learning.

\section{Conclusions and Future Direction}

The project component in CURIE 2000 was a departure from previous years in that the project details were not clearly delineated, nor did the task have a simple "right or wrong" solution. The project was purposely complicated by social, political, and economic issues. It fell to the 40 students enrolled in the program to sort out the scope of the problem from information presented in a non-classroom setting, with openly acknowledged subjectivity affecting the results. We were fairly certain, but not absolutely sure, that newly formed teams of high school girls_-girls from all over the country with different backgrounds and different academic orientations_-would be able to tackle such a complex project. The forty girls (22 white and Asian, 18 AfricanAmerican and Hispanic) who spent July 9-15, 2000 on Cornell University campus working on "The CURIE River Basin" were definitely up to the task. Were there frustrations? Were students at times uncomfortable and confused? Absolutely. But the participants were expected to succeed, and they more than rose to the challenge.

We are convinced that future CURIE projects should maintain a high level of intellectual sophistication. We will focus on building into the program support structures to ensure that students succeed, gain confidence and acquire a sense of excitement about what they can achieve through the study and practice of engineering. We will continue to increase the level of training for our program assistants, and to brief all our faculty and presenters carefully about the project 
so that they, if they chose, may discuss how their field of engineering relates to the core project. We will devote greater effort toward building effective teamwork both in problem-solving and in group presentations. We will be explicit about the difficulty and complexity of the project. We will make clear that the purpose is to provide challenge to a high functioning group. We will emphasize that success is tied to the efforts of the individual students, and the group as a whole.

We want to articulate the expectation of success because women and ethnic minority students are often subjected to social stereotyping, and subsequent low expectations, in engineering. Steele has researched the impact on learning for students under stereotype threat. He makes the point that, for these students, it is critical to emphasize that the high expectations placed on them derive from the students' abilities. Such statements of confidence elicit the best results. ${ }^{10}$

The model we use for this comprehensive, project-based, cross-disciplinary instruction could translate, with some modifications, to a meaningful first-year experience for engineering students. First-year engineering students rarely get an opportunity to experience an engineering problem in all its richness, including the social, political, communication, ethical and economic constraints that have an impact on whether a particular technical solution is implemented. The authors advocate introducing students early in their academic careers to the broad relevance and social impact of engineering. We suggest that such an opportunity would make for higher retention of women and minorities and would attract more non-traditional students to the field.

\section{References}

1. Women, Minorities, and Persons With Disabilities in Science and Engineering: 2000, National Science Foundation, September 2000.

2. Land of Plenty, Diversity as America's Competitive Edge in Science, Engineering and Technology, Report of the Congressional Commission on the Advancement of Women and Minorities in Science, Engineering and Technology Development, July 2000.

3. Wulf, William A., Moving Beyond Individual Programs to Systemic Change, 1999 WEPAN National Conference.

4. Felder, R. M. and Brent, R., Navigating the Bumpy Road to Student-Centered Instruction, College Teaching, 44 (2), 43-47, 1996.

5. Bordogna, J., Making Connections: The Role of Engineers and Engineering Education, The Bridge, Volume 27, Number 1 - Spring 1997.

6. Imperatives in Undergraduate Engineering Education: Issues and Actions. Report of an NSF Ad Hoc Task Force. August. Washington, D.C.: National Science Foundation, 1989.

7. DESSERT, computer software, International Institute for Applied Systems Analysis and Institute for Water and Environmental Problems. URL: www.iiasa.ac.at/Research/WAT/docs/desert.html.

8. Woods, D.R., Problem-based learning: How to gain the most from PBL. Waterdown, Ontario: Donald R. Woods, 1994.

9. 2000 CURIE Report, Women's Programs in Engineering, Cornell University.

10. Steele, C. M., How to Reduce Stereotype Threat, Thin Ice, The Atlantic Monthly, August 1999.

\section{K-Y. DAISY FAN}

Daisy Fan is a Ph.D. candidate in the School of Civil \& Environmental Engineering at Cornell University. She conducts research in environmental systems engineering with a focus in optimization. Throughout her graduate 
studies, Daisy has participated in outreach programs that bring awareness of engineering to elementary and high school classrooms. In 1999, Daisy was Chair of the Expanding Your Horizons Conference for middle school girls and their guardians and teachers at the Cornell University site.

KRISHNA S. ATHREYA

Krishna Athreya is the Director of Women's Programs in Engineering at Cornell University. She received her Ph.D. in Experimental Condensed Matter Physics from Iowa State University. Prior to taking her current position, she served as the Coordinator for Iowa State's Program for Women in Science and Engineering.

ROBIN J. BURT

Robin Burt is the Assistant Director for Women's Programs in Engineering in the College of Engineering at Cornell University. She also serves as the Communications Coordinator for the Office of Instructional \& Research Support in the College of Engineering, supporting the College's cooperative learning program. She received her B.A. in History from the University of Washington. Prior to working in student services, she worked in public affairs, development and non-profit administration. 